\title{
Sexual function outcomes following fracture of the penis
}

\author{
Gregory J. Nason, MRCSI; Barry B. McGuire, FRCS(Urol); Stephen Liddy, MB, BCh; Aisling Looney, MB, BCh; \\ Gerald M. Lennon, FRCS(Urol); David W. Mulvin, FRCS; David J. Galvin, FRCS(Urol); David M. Quinlan, FACS
}

Department of Urology, St Vincent's University Hospital, Elm Park, Dublin, Ireland

See related article on page 258 .

Cite as: Can Urol Assoc J 2013;7(7-8):252-7. http://dx.doi.org/10.5489/cuaj.199 Published online August 19, 2013.

\section{Abstract}

Introduction: Fracture of the penis is a rare urological emergency which occurs as a result of abrupt trauma to an erect penis. There is paucity of data regarding long-term sexual function or erectile potency following fracture of the penis. The aim of this study is to objectively assess the overall sexual function following fracture of the penis.

Methods: A retrospective analysis of 21 penile fractures was performed. A voluntary telephone questionnaire was performed to assess long term outcomes using three validated questionnaires-the Erection Hardness Grading Scale, the International Index of Erectile Function (IIEF-5) and the Brief Male Sexual Function inventory (BMSFI).

Results: The mean age was 33.1 years (range: 19-63). The median follow up was 46 months (range: 3-144). All fractures were a result of sexual misadventure and all were surgically repaired. There were two concomitant urethral injuries. Seventeen patients were contactable. Fourteen patients demonstrated no evidence of erectile dysfunction (ED) (IIEF-5>22), 1 patient reported symptoms of mild ED (IIEF-5, 17-21) and one patient reported mild to moderate ED (IIEF-5, 12-16). No patients reported insufficient erection for penetration (EHGS: 1 or 2). Regarding the overall BMSFI, 13 (83\%) patients were mostly satisfied or very satisfied with their sex life within the previous month.

Conclusion: In a small surgical series of men with penile fracture managed within a short time frame from presentation, we demonstrate erectile potency is maintained. Long-term overall sexual satisfaction is promising.

\section{Introduction}

Penile fracture is a rare urological emergency, and is defined as a primary rupture of the tunica albuginea of the penile corpora cavernosum occurring in the tumescent state. ${ }^{1}$ The etiology of the injury is usually abrupt trauma by forceful bending of an erect penis. In Western society, the most common cause is fracture during sexual intercourse. ${ }^{2}$ Many recently reports have come from Middle Eastern countries where the fractures are usually caused by "taqaandan" or forcefully bending the erect penis to achieve detumescence. ${ }^{3,4}$ Penile fracture has a typical clinical presentation. Patients report hearing a snapping sound during the sexual act, followed by immediate pain and penile detumescence, in addition to the emergence of large edema, hematoma and penile deformity. ${ }^{5}$

In the past, conservative treatment was the standard treatment for penile fractures. However, such an approach was associated with a high incidence of complications, such as curvature, palpable nodule and erectile dysfunction in up to $50 \%$ of patients. ${ }^{6}$ Immediate surgical repair is now the standard of care and is superior to a non-operative management due to excellent long term outcomes. ${ }^{7-9}$

Data regarding sexual function following fracture of the penis is lacking. In a series of men presenting with penile fracture, we describe the long-term potency and overall sexual function following prompt surgical repair.

\section{Methods}

Written informed consent was obtained from all patients within this study and all patient information was dealt with confidentially and only for the purpose of the study; no third party was involved. The study was approved at the monthly departmental research meeting. All contact details were verified with the patients' general practitioner.

During the 2000-2012 period, 21 patients were admitted to our unit with a fracture of the penis. All were surgically treated. Patients' medical records and operative notes were retrospectively reviewed for demographic details, mechanism of injury, time to presentation and surgery, physical examination findings, outcomes and follow-up. All patients were admitted through the emergency department. All procedures were carried out by a consultant urological surgeon. All repairs were performed using a degloving circumcision. Penile and urethral injuries were identified and repaired individually with non-absorbable Prolene (Ethicon Endo-Surgery, Inc., Somerville, NJ) sutures and absorbable Vicryl (Ethicon 


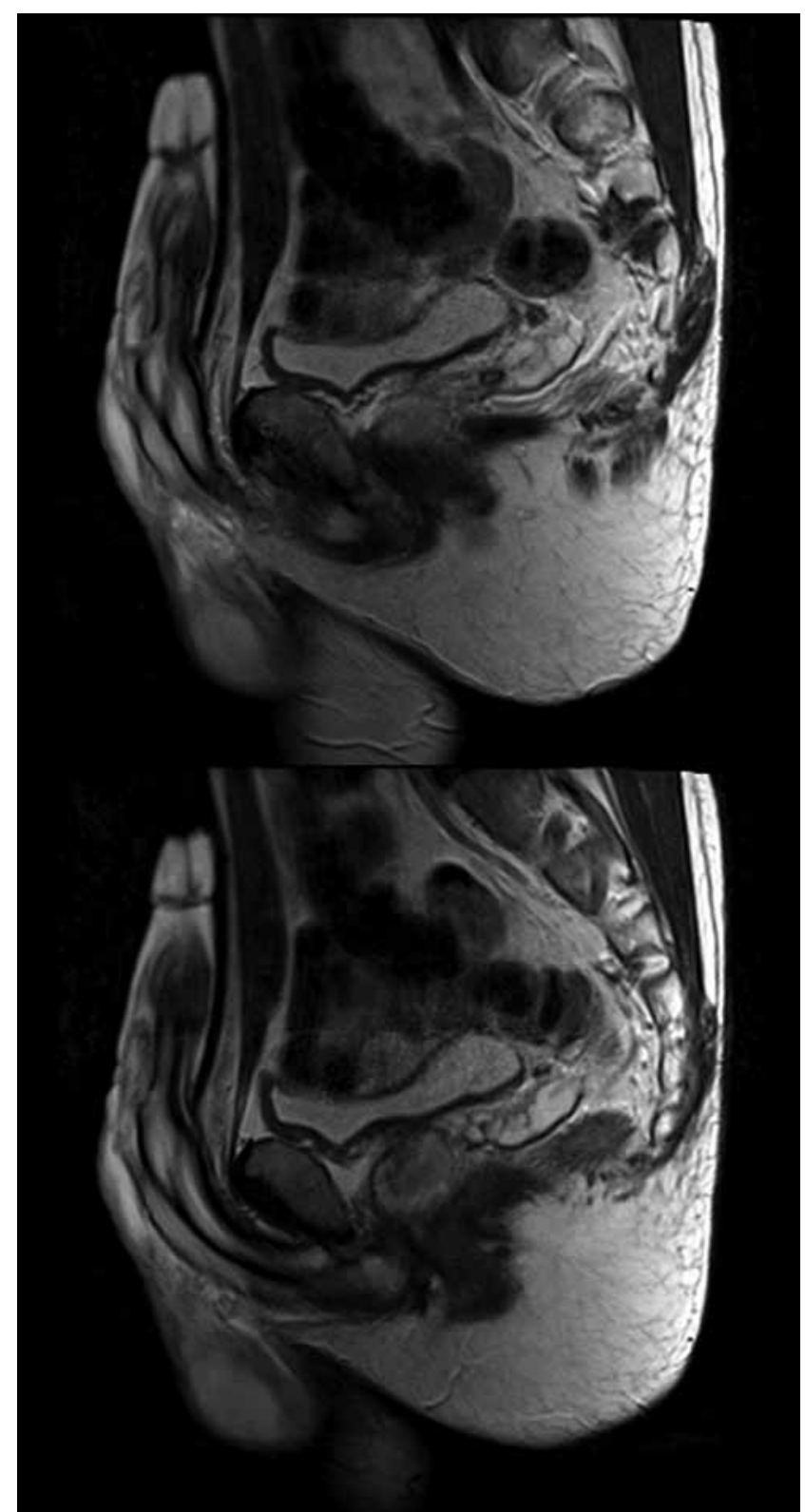

Fig. 1. There is a focal area of discontinuity in the tunica albuginea overlying the right corpus cavernosum with overlying abnormal focal abnormal signal intensity likely representing an associated hematoma. The area indicating discontinuity is about $5 \mathrm{~cm}$ proximal to the tip of the glands penis.

Endo-Surgery, Inc., Somerville, NJ) sutures, respectively. Urethral injuries were closed with an end to end anastomosis. Urinary catheters were placed intra-operatively. Patients were reviewed as out-patients 6 weeks postoperatively.

A voluntary telephone survey was also carried out by two of the investigators (GJN, SL). The telephone survey involved three recognized scoring systems to objectively assess sexual function and erectile potency post-fracture of the penis.

The International Index of Erectile Function (IIEF-5) is an abbreviated questionnaire focusing on erectile function and intercourse satisfaction for the diagnosis of the presence and severity of erectile dysfunction (ED) (5 questions, maximum score 25). ${ }^{10}$ Erection hardness is a fundamental component of erection function. The Erection Hardness Grading Scale (EHGS) is a single question, a 4-point scale for ED, which provides a reliable measure of erection hardness. ${ }^{11}$ The Brief Male Sexual Function Inventory (BMSFI) provides a selfreported measure of current sexual functioning. It covers three functional domains (sexual drive, erectile function and ejaculatory function), as well as problem assessment of these functional domains and overall satisfaction. ${ }^{12}$

\section{Results}

Between 2000 and 2012, 21 males were admitted to our unit with fracture of the penis. The mean age was 33.1 years (range: 19-63). The median follow-up was 46 months (range: 3-144). The mean time to presentation from injury was 16.3 hours (range: $8-40$ ) and the mean time from injury to surgical intervention was 27.3 hours (range: 12-46). All fractures were a result of sexual misadventure, one involving masturbation. Of the 20 involving sexual intercourse, 13 were sustained in a female on top position. Fifteen $(71.4 \%)$ fractures were encountered immediate detumescence.

The presenting symptoms included pain $(\mathrm{n}=21 ; 100 \%)$, swelling $(\mathrm{n}=17 ; 80.9 \%)$, inability to regain an erection $(\mathrm{n}=17 ; 80.9 \%)$, visible hematuria $(\mathrm{n}=6 ; 28.6 \%)$ and voiding difficulty $(\mathrm{n}=2 ; 9.5 \%)$.

Four patients underwent preoperative radiological imaging. Two had magnetic resonance imaging (MRI) scans (Fig. 1) and 2 had cavernosograms; all patients showed evidence of cavernosal rupture. Radiological imaging was sought in these cases due to an ambiguous history or examination; however, it did not alter the prompt surgical repair. All 4 patients presented $>24$ hours after the initial insult; however, they maintained erections post-injury.

Patients with visible hematuria had intra-operative urethrograms. Two patients showed evidence of concomitant urethral injury (one patient had a full thickness $2-\mathrm{cm}$ urethral tear and the other patient had a partial superficial tear). The full thickness tear was closed with an end to end anastomosis. On review at 6 weeks, both patients denied any lower urinary tract symptoms and uroflowometry demonstrated objective evidence urethral patency (Patient 1: Qmax $21.5 \mathrm{~mL} / \mathrm{s}$, post-void residual volume [PVR] $0 \mathrm{~mL}$ and patient 2: Qmax $33.2 \mathrm{~mL} / \mathrm{s}$, PVR $0 \mathrm{~mL}$ ). Both patients were followed up without complication for 1 year.

For the telephone survey, we were able to contact 17 $(81 \%)$ patients. Sixteen $(94.1 \%)$ are currently or have been sexually active within the past 3 months (Table 1.) Two patients $(11.7 \%)$ routinely use oral sildenafil $75 \mathrm{mg}$, one of whom used this medication prior to his penis fracture. 
Nason et al.

\begin{tabular}{|c|c|c|c|c|c|c|c|c|c|c|c|}
\hline \multirow[t]{2}{*}{ Age } & \multirow[t]{2}{*}{ Sexually active } & \multirow[t]{2}{*}{ EHGS } & \multicolumn{5}{|c|}{ IIEF-5 } & \multicolumn{4}{|c|}{ MBSFI } \\
\hline & & & 1 & 2 & 3 & 4 & 5 & Drive & Erection & Ejaculation & Overall \\
\hline 28 & + & 4 & 4 & 4 & 4 & 5 & 5 & 5 & 5 & 4 & 5 \\
\hline 21 & + & 3 & 4 & 4 & 4 & 2 & 2 & 5 & 4 & 3 & 4 \\
\hline 43 & + & 4 & 4 & 4 & 5 & 5 & 5 & 4 & 4 & 4 & 5 \\
\hline 29 & + & 3 & 4 & 4 & 4 & 5 & 5 & 2 & 2 & 2 & 1 \\
\hline 25 & + & 4 & 5 & 5 & 5 & 5 & 5 & 5 & 5 & 3 & 5 \\
\hline 26 & + & 3 & 5 & 5 & 5 & 5 & 3 & 4 & 4 & 4 & 4 \\
\hline 36 & + & 4 & 4 & 4 & 2 & 4 & 5 & 4 & 4 & 4 & 4 \\
\hline 29 & + & 4 & 4 & 5 & 5 & 5 & 5 & 4 & 3 & 4 & 4 \\
\hline 19 & + & 3 & 4 & 5 & 5 & 5 & 5 & 4 & 5 & 4 & 5 \\
\hline 58 & + & 3 & 5 & 5 & 5 & 5 & 5 & 4 & 5 & 5 & 5 \\
\hline 47 & + & 4 & 4 & 5 & 5 & 5 & 5 & 5 & 4 & 3 & 4 \\
\hline 29 & + & 4 & 5 & 5 & 5 & 5 & 5 & 5 & 4 & 3 & 5 \\
\hline 37 & + & 4 & 5 & 5 & 5 & 5 & 5 & 4 & 4 & 3 & 4 \\
\hline 33 & + & 4 & 5 & 5 & 5 & 5 & 5 & 5 & 4 & 5 & 4 \\
\hline 28 & + & 3 & 5 & 5 & 3 & 5 & 5 & 4 & 3 & 4 & 4 \\
\hline 19 & + & 4 & 5 & 5 & 5 & 5 & 5 & 4 & 4 & 4 & 4 \\
\hline 63 & - & 3 & - & - & - & - & - & - & - & - & - \\
\hline
\end{tabular}

IIEF-5

In the past 6 months, all patients reported high or very high confidence in their ability to achieve and maintain an erection. All patients reported that their erections on stimulation

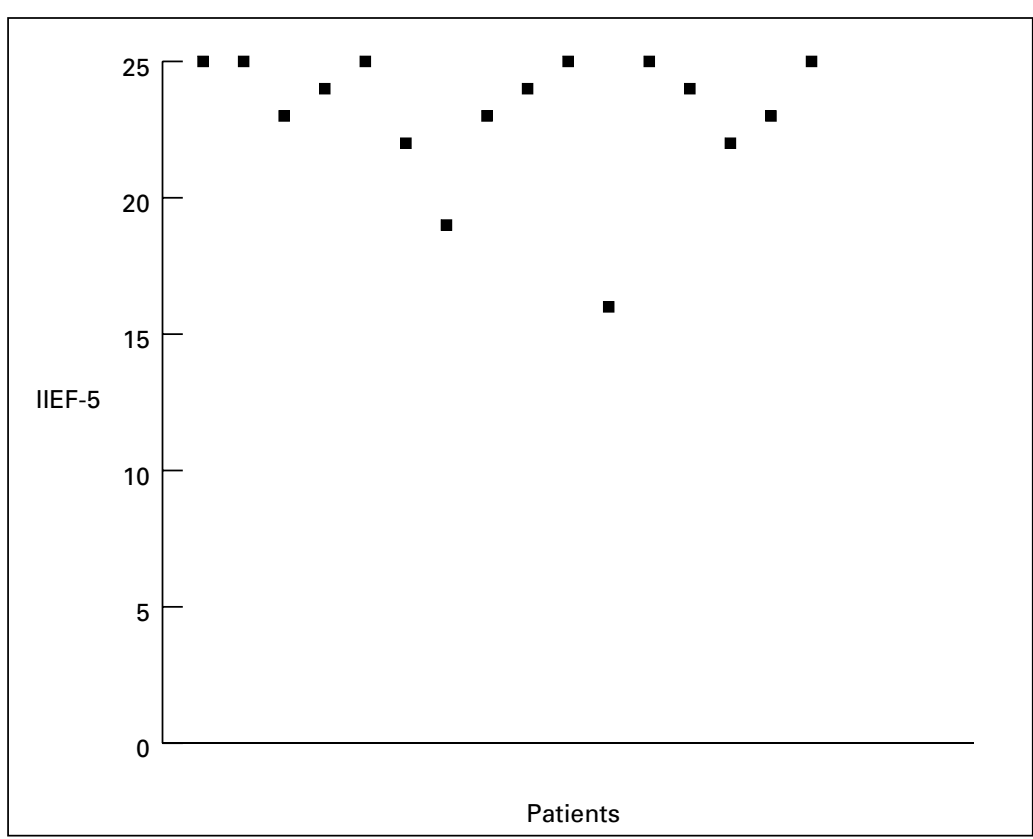

Fig. 2. Postoperative International Index of Erectile Function (IIEF-5) score for all patients who underwent surgical correction of penile fracture. The IIEF-5 score is the sum of the ordinal responses to the 5 items (maximum 25); Score 5 to 7 indicates severe erectile dysfunction (ED); 8 to 11 moderate ED; 12 to 16 mild to moderate ED; 17 to 21 mild ED; and 22 to 25 no ED. were hard enough to achieve and maintain penetration most or all of the time. Two $(12.5 \%)$ patients found it difficult or very difficult to maintain an erection for intercourse. Fourteen $(87.5 \%)$ patients reported attempts at sexual intercourse as being satisfactory most or all of the time. Fourteen patients demonstrated no evidence of erectile dysfunction (IIEF-5 >22), 1 patient reported symptoms of mild ED (IIEF-5, 17-21) and 1 patient reported mild to moderate ED (IIEF-5 range: 12-16) (Fig. 2).

\section{BMSFI}

Thirteen $(83 \%)$ patients felt they had no problem with sexual drive or erectile function within the past month. Ten patients $(66.7 \%)$ felt they had no problem or a very small problem with their ability to ejaculate within the past month. Overall, 13 $(83 \%)$ patients were mostly satisfied or very satisfied with their sex life within the past month. One patient remained neither satisfied nor dissatisfied. Two patients were mostly dissatisfied with their sex life (1 patient felt this was unrelated to the fracture of penis, while the other complained of his "penis feeling different since the injury").

\section{EHGS}

On stimulation, $10(58.8 \%)$ patients reported a maximum score of 4 (penis is completely hard and fully rigid). Seven $(41.2 \%)$ patients reported a score of 
3 (penis is hard enough for penetration, but not completely hard) (Fig. 3). No patients reported insufficient erection for penetration.

\section{Discussion}

Penile fracture is an uncommon urological emergency and as a result there is little data describing sexual function postinjury. Most large published series come from the Middle East where the practice of "penile cracking" (or manipulation at masturbation) is the main cause of the fracture.,13,14 The practice of "taqaandan" is not common in Ireland and the mechanism of all fractures in our series was sexual misadventure. In Western countries, sexual intercourse with the female on top account for most cases of penile fracture, probably due to the mechanical force exerted on the erect penis. Despite mechanism of injury, surgical intervention is now the standard of care and repair of the tunica albuginea without delay is recommended in most contemporary series (Fig. 4). ${ }^{8,9,15,16}$ Until the 1970s conservative treatment for managing penile fractures was described. Urethral catheterization, compression bandages and consistent cooling, combined with anti-inflammatory, anti-erectile, antibiotic and analgesic therapy were reported by Thompson. ${ }^{17}$ However, retrospective analysis of this conservative treatment showed an unacceptable rate of immediate and late complications, such as persisting hematoma, infections and abscesses, deformity of the penis, pulsatile diverticulum, fistula, ED and decrease in turgidity. ${ }^{17}$

We do not routinely use preoperative imaging in cases of penile fracture. The use of preoperative radiological imaging is controversial; in our unit, imaging is used in cases of ambiguous history, examination or presentation. Although clinical examination can accurately predict most penile fractured, ${ }^{1,3}$ penile ultrasound, MRI or cavernosography have been used to locate the rupture of the tunica albuginea. ${ }^{18,19}$

In addition, debate remains regarding the gold standard surgical approach for repair, and several techniques with positive outcomes have been described. These techniques include penile degloving, ${ }^{1,13,14,16}$ a direct longitudinal incision over the injury, ${ }^{13,14,20}$ an inguino-scrotal approach, ${ }^{9,21}$ a midline incision on the raphe ${ }^{1,22}$ and a suprapubic approach. ${ }^{23}$ Although we routinely use a degloving technique in our unit, the approach used depends upon degree of swelling and hematoma, location of urethral injury and surgeon preference. We used non-absorbable sutures in all cases in this series. There is no Level 1 evidence for which type of suture should be used, and traditional teaching would advoate the use of non-absorbable sutures. Both absorbable $\mathrm{e}^{13,16,24}$ and non-absorbable ${ }^{3,14}$ sutures have been described for repair of the tunica rupture.

The long-term effects of delayed presentations and the optimal timing of subsequent intervention have caused some

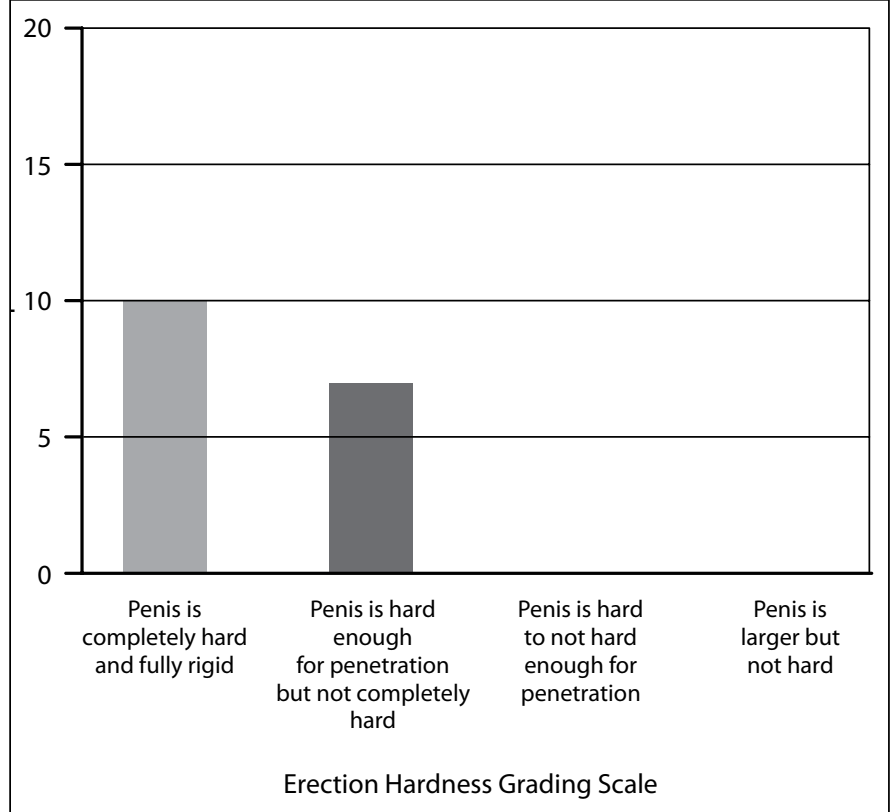

Fig. 3. Erection Hardness Grading Scale (EHGS) score for all of the patients assessed.

debate. Kozacioglu and colleagues report no serious deformity or ED as a consequence of delay in surgery within a given time frame in 56 penile fractures, in terms of number of hours to presentation (mean number of hours from trauma to repair $11.3 \pm 8.5$ hours). ${ }^{25}$ Similarly, el-Assmy and colleagues noted no difference in serious long- term complications between those who were treated surgically following an early (within 24 hours) or delayed (up to 7 days) presentation. ${ }^{13}$ Of their cohort, $17 \%(n=31)$ presented as delayed fractures. Despite no serious long-term complications with delayed presentations, immediate surgical intervention has lower morbidity, shorter hospital stay, rapid functional recovery, as well as no serious long-term sequelae. ${ }^{14,26}$ Contrary to this, Nasser and colleagues described a delayed surgical approach following a conservative approach of 7 to 10 days to allow the initial edema and hematoma to settle. ${ }^{27}$

Little reproducible data has been published regarding the objective analysis sexual function following fracture of the penis. Zargooshi and colleagues reported excellent longterm sexual function outcomes in 373 patients from Iran. ${ }^{3}$ As expected, $76.4 \%$ were due to the practice of "taqaandan." Postoperatively, of the 217 (58.2\%) patients who had partners, 214 (98.6\%) were potent. The EHGS score was 4 in 203 cases and 3 in 11 cases. ED in the remaining 3 patients could not be explained by penile fracture. We noted similarly high EHGS scores in our cohort (100\%; EHGS 3 or 4).

Erection hardness and implied erection function is one of the main determinants involved in male sexual function. This does not imply that erectile potency is a dominant factor in overall sexual satisfaction, but it is an objective 
Nason et al.

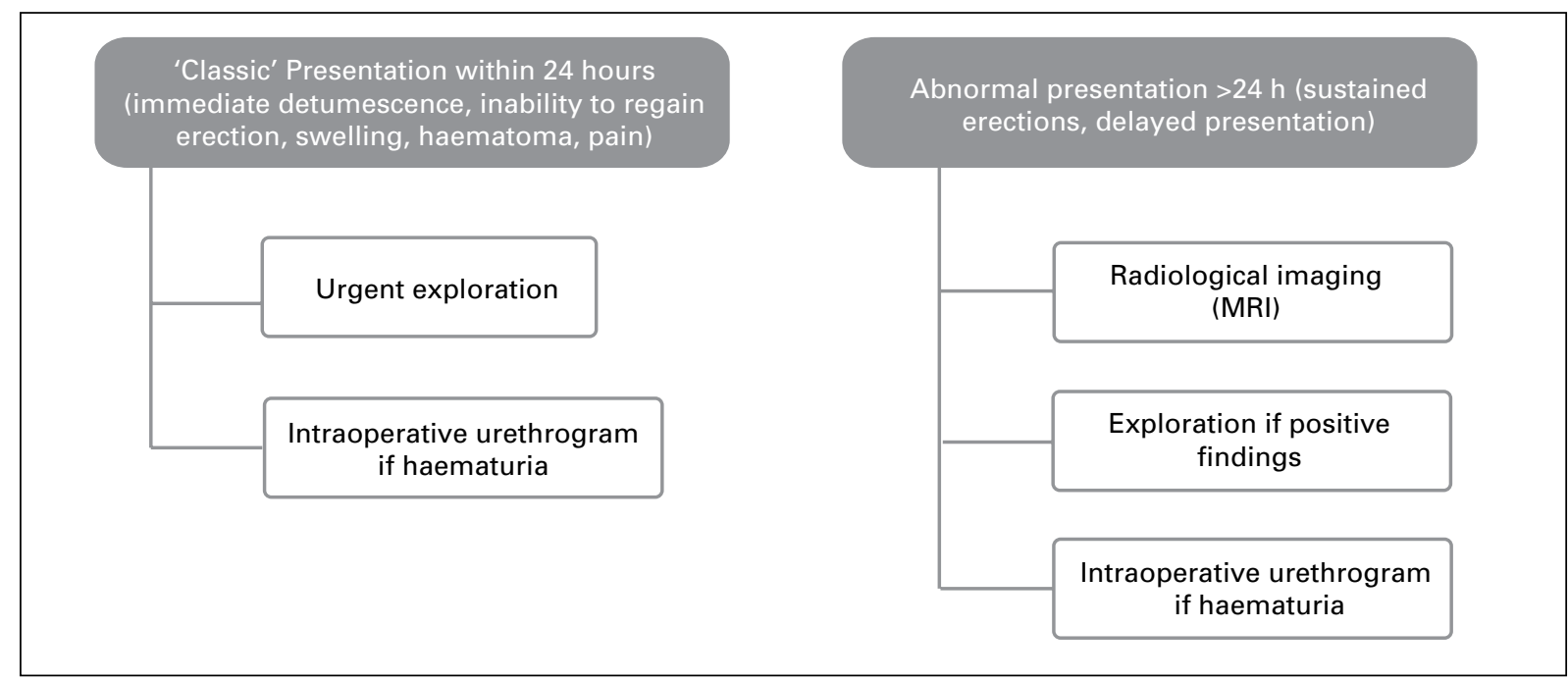

Fig. 4. Management algorithm for management of penile fractures.

measurement. The BMFSI, initially designed by O'Leary in 1995 to provide a self-reported measure of current sexual functioning, was designed to be brief, self-administered and clinically useful. The BMSFI was selected as an overall grading system of sexual function as opposed to the EHGS and IIEF-5 which focus on erectile potency. O'Leary and colleagues concluded that due to the multidimensional aspects of sexual function, a summary score from the BMSFI was not recommended. ${ }^{12}$ Despite this, our data suggest that penile fractures are not associated with low scores in drive, erectile function, ejaculation or perception (mean scores: 4.3; $4 ; 3.45$; and 4.4, respectively) and an overall satisfaction was maintained following recovery from penile fractures (mean score 4.1). Our data suggest that, in a Western cohort of penile fractures following sexual intercourse, long-term erectile potency is preserved and overall sexual function is maintained. To the best of our knowledge, at the time of writing, this is the first study to objectively assess sexual function (IIEF-5, BMSFI, EHGS) following fracture of the penis in Western society.

Our study has a number of limitations. This is a retrospective study of a small number of patients and we did not assess erectile function prior to injury; however, penile fracture is a rare injury and there is limited objectively analysed data available. Each questionnaire used in this study is a self-assessment and patients' opinions may vary; however, the IIEF-5 and EHGS are designed to objectively assess erection function as a key parameter of overall sexual function. Sexual function is not solely determined by erectile function and the BMSFI was used to assess overall function and satisfaction. Although the telephone survey used in our study was not validated, telephone surveys have been used in the past to assess sexual function. We did not require another patient visit to assess function after a long period.

\section{Conclusion}

In this small surgical series of men with penile fracture managed within a short time frame from presentation, we demonstrate that erectile potency is maintained and long-term overall sexual satisfaction is promising.

Competing interests: None declared.

This paper has been peer-reviewed.

\section{References}

1. Mazaris $E M$, Livadas $K$, Chalikopoulos $D$, et al. Penile fractures: immediate surgical approach with a midline ventral incision. BJU Int 2009;104:520-3. http://dx.doi.org/10.1111/j.1464-410X.2009.08455.x

2. Kamdar C, Mooppan UM, Kim H, et al. Penile fracture: preoperative evaluation and surgical technique for optimal patient outcome. BJU Int 2008;102:1640-4. http://dx.doi.org/10.1111/i.1464410X.2008.07902.x

3. Zargooshi J. Sexual function and tunica albuginea wound healing following penile fracture: An 18-year follow-up study of 352 patients from Kermanshah. Iran. J Sex Med 2009;6:1141-50. http://dx.doi. org/10.1111/i.1743-6109.2008.01117.x

4. Ateyah A, Mostafa T, Nasser TA, et al. Penile fracture: surgical repair and late effects on erectile function. J Sex Med 2008;5:1496-502. http://dx.doi.org/10.1111/i.1743-6109.2007.00769.x

5. Mydlo JH, Hayyeri M, Macchia RJ. Uretrography and cavernosography imaging in a small series of penile fracture: A comparison with surgical findings. Urology 1998;51:616-9. http://dx.doi.org/10.1016/ S0090-4295(97)00701-2

6. McAninch JW, Santucci RA. Genitourinary trauma P.C. Walsh, A.B. Retik, E.D. Vaughan (Eds.), Campbell's Urology (8th ed.), WB Saunders, Philadelphia; 2002.

7. Muentener $M$, Suter $S$, Hauri $D$, et al. Long-term experience with surgical and conservative treatment of penile fracture. J Urol 2004;172:576-9. http://dx.doi.org/10.1097/01.ju.0000131594.99785.lc

8. Gamal WM, Osman MM, Hammady A, et al. Penile fracture: long-term results of surgical and conservative management. J Trauma 2011;71:491-3. http://dx.doi.org/10.1097/TA.0b013e3182093113

9. Ralph D, Gonzalez-Cadavid N, Mirone V, et al. Trauma, gender reassignment, and penile augmentation. J Sex Med 2010;7(4 Pt 2):1657-67. http://dx.doi.org/10.1111/i.1743-6109.2010.01781.x

10. Rosen RC, Cappelleri IC, Smith MD, et al. Development and Evaluation of an Abridged, 5-Item Version of the International Index of Erectile Function (IIEF-5) as a Diagnostic Tool for Erectile Dysfunction. Int J Imp Res 1999;11:319-26. 
11. Mulhall JP, Goldstein I, Bushmakin AG, et al. Validation of erection hardness score. I Sex Med 2007;4:1626-34. http://dx.doi.org/10.1111/i.1743-6109.2007.00600.x

12. $0^{\prime}$ Leary MP, Fowler FJ, Lenderking WR, et al. A brief male sexual function inventory in urology. Urology 1995;46:697-706. http://dx.doi.org/10.1016/S0090-4295(99)80304-5

13. el-Assmy A, el-Tholoth HS, Mohsen T, et al. Does timing of presentation of penile fracture affect outcome of surgical intervention? Urology 2011;77:1388-91. http://dx.doi.org/10.1016/i.urology.2010.12.070

14. Ibrahiem el-HI, el-Tholoth HS, Mohsen T, et al. Penile fracture: long-term outcome of immediate surgical intervention. Urology 2010;75:108-11.

15. García Gómez B, Romero J, Villacampa F, et al. Early treatment of penile fractures: our experience. Arch Esp Urol 2012;65:684-8.

16. Koifman L, Barros R, Júnior RA, et al. Penile fracture: diagnosis, treatment and outcomes of 150 patients. Urology 2010;76:1488-92. http://dx.doi.org/10.1016/i.urology.2010.05.043

17. Thompson RF. Rupture of the penis. J Urol 1954;71:226.

18. Fergany AF, Angermeier KW, Montague DK. Review of Cleveland Clinic experience with penile fracture. Urology 1999;54:352-5. http://dx.doi.org/10.1016/S0090-4295(99)00115-6

19. Kervancioglu S, Ozkur A, Bayram MM. Color Doppler sonographic findings in penile fracture. J Clin Ultrasound 2005;33:38-42. http://dx.doi.org/10.1002/ju.20078

20. Ozen HA, Erkan I, Alkibay $\mathrm{T}$, et al. Fracture of the penis and long-term results of surgical treatment. $\mathrm{Br} J$ Urol 1986;58:551-2. http://dx.doi.org/10.1111/i.1464-410X.1986.tb05466.x
21. Seftel AD, Haas CA, Vafa A, et al. Inguinal scrotal incision for penile fracture. J Urol 1998;159:182-4. http://dx.doi.org/10.1016/S0022-5347(01)64051-5

22. Su LM, Sutaria PM, Eid JF. Repair of penile rupture through a high-scrotal midline raphe incision. Urology 1998;52:717-9. http://dx.doi.org/10.1016/S0090-4295(98)00237-4

23. Konnak JW, Ohl DA. Microsurgical penile revascularization using the central corporeal penile artery. J Urol 1989; 142:305-8.

24. Uygur MC, Gulerkaya B, Altug U, et al. 13 years' experience of penile fracture. Scand I Urol Nephrol 1997;31:265-6. htrp://dx.doi.org/10.3109/00365599709070345

25. Kozacioglu $Z$, Degirmenci $T$, Arslan $M$, et al. Long-term significance of the number ofhours until surgical repair of penile fractures. Urol Int 2011;87:75-9. http://dx.doi.org/10.1159/000325589

26. Yapanoglu T, Aksoy Y, Adanur $S$, et al. Seventeen years' experience of penile fracture: conservative vs. surgical treatment. J Sex Med 2009;6:2058-63. http://dx.doi.org/10.1111/i.1743-6109.2009.01296.x

27. Nasser TA, Mostafa T. Delayed surgical repair of penile fracture under local anesthesia. J Sex Med 2008:5:2464-9.

Correspondence: Mr Gregory Nason, Department of Urology, St Vincent's University Hospital, Elm Park, Dublin 4, Ireland; fax: +35312773508; nasong@tcd.ie.ca 